\title{
Synthesis of Rice Straw as Biosorbent for Colour Removal in Batik Industrial Waste which is Represented by Methylene Blue
}

\author{
Nakesamas Putut Prilininta ${ }^{1, *}$, and Oktrianto ${ }^{1}$ \\ ${ }^{1}$ Department of Chemical and Green Process Engineering, Surya University, Tangerang 15810, Indonesia
}

\begin{abstract}
Use of rice straw as a biosorbent for water treatment in batik industry is not fully developed. Liquid waste for the colour's adsorption using rice straw biosorbent represented by methylene blue solution. Rice straw biosorbent has been activated by $\mathrm{HNO}_{3} 1 \mathrm{M}$ and $\mathrm{NaOH} 0,75 \mathrm{M}$. Then characterized using Scanning Electron Microscopy with Energy Dispersive Spectroscopy (SEM EDS) dan Fourier Transform Infrared (FTIR) Spectroscopy. The variation of dosage and drying temperature applied to know the optimum dosage for utilization of biosorbent and optimum drying temperature for biosorbent synthesis. The equilibrium were fitted to Langmuir isotherm and Pseudo Order 2 kinetics. The optimum adsorption obtained in $1,67 \mathrm{gr} / \mathrm{L}$ biosorbent with $100^{\circ} \mathrm{C}$ drying temperature in $4 \mathrm{ppm}$ methylene blue waste simulation solution with $95.27 \%$ adsorption capacities and $4 \mathrm{ppm}$ batik industrial waste solution with $30.59 \%$ adsorption capacities.
\end{abstract}

\section{Introduction}

Batik is one of the world cultural heritage derived from Indonesia. Batik becomes an important part in industrial growth in Indonesia, especially in batik producing area. Productivity of batik does not only affect the increase of regional income, but also impact on other problems, especially environmental problems. One of the environmental problem is caused by batik production process that produced liquid waste which comes from residual of batik colouring process. The liquid waste by some industries directly discharged into the river without treatment [1].

Rivers have the ability to clean themselves (self purification). But if the waste is discharged continuously and exceeds the self purification capability of the river, it will result in the occurrence of river pollution [2]. Colour is the easiest parameter to determine whether the river is clean or not. The clean river has a clear flow of water. If the river flow is not clear, it can be indicated that the river is not suitable for daily needs. Rivers in batik industrial areas have been polluted dyes derived from residual of batik colouring process [3]. Based on these parameters can be indicated that the river is not feasible for the continuity of the river ecosystem and the needs of water to surrounding communities.

There are several alternatives to handle the waste problem. The adsorption method becomes one of the ways to absorb the dye on batik industrial waste. This study also focused on using natural material adsorbent (biosorbent) derived from agricultural waste as an alternative to conventional adsorbents. Agricultural wastes are selected as the basic ingredients for the synthesis of biosorbents because of their abundant availability. In addition, its use can be optimal because it does not compete with anything [4]. There are various agricultural wastes, such as coconut shells, rice husks, rice stalks, corncobs, palm oil bunches and others. Agricultural waste is a material that has the potential to be processed into biosorbent [5]. Agricultural waste used in this research is rice straw. Rice straw is chosen because its availability is very abundant and rarely reused. After the harvest season, rice straws are directly burned without being processed first [6]. Rice straw contains $\mathrm{C}, \mathrm{O}, \mathrm{H}$ and $\mathrm{N}$ content of $87 \%$ of its total weight and $\mathrm{Si}(4.6 \%), \mathrm{K}(2.5 \%), \mathrm{P}(0.5 \%), \mathrm{Ca}(0.3 \%)$ And Mg (0.3\%) (Wang, 2007, p.315). These elements content are beneficial to adsorption process, so that rice straw is potentially processed into biosorbent [7].

This study made biosorbent from rice straw that activated using $\mathrm{HNO}_{3} 1 \mathrm{M}$ and $\mathrm{NaOH} 0.75 \mathrm{M} . \mathrm{HNO}_{3}$ and $\mathrm{NaOH}$ were selected become media activation based on Rocha's research, et al [8]. Both were able to make pore of the rice straw have a greater absorbence to adsorbate. Then the biosorbent will be applied to absorb the dissolved dyes in the liquid waste of batik industrial. This research uses methylene blue to represent liquid waste of batik industrial. Methylene blue is a cationic dye commonly used by textile industry [9].

The objective of this work were to convert rice straw to biosorben with high sorption capacity, and to examine potential application of this new biosorben in batik's colour wastewater treatment.<smiles>CN(C)c1ccc2nc3ccc(=[N+](C)C)cc-3sc2c1</smiles>

Fig. 1. Chemical structure of Methylene Blue.

Corresponding author: nakesamasprilininta@gmail.com 


\section{Materials and Methods}

\subsection{Materials}

Rice straw and batik industrial waste were collected from Pekalongan City, Central Java, Indonesia. Methylene blue (Merck), $\mathrm{NaOH}$ (Merck) and $\mathrm{HNO}_{3}$ (65\%, Pudak Scientific). All solution were prepared by using distilled water.

\subsection{Preparation of modified biosorbent}

Rice straw washed by water, dried in an oven at $60^{\circ} \mathrm{C}$ for 8 hours. And then crushed to obtain a small size. This material called as SMP. $10 \mathrm{~g}$ of SMP was activated by $50 \mathrm{~mL}$ of $\mathrm{HNO}_{3} 1 \mathrm{M}$ and agitated for 1 hour at room temperature. Next, the material washed by water to removed the excess acid. After the $\mathrm{pH}$ was neutral, 10 $\mathrm{g}$ of SMP activated by $100 \mathrm{~mL}$ of $\mathrm{NaOH} 0,75 \mathrm{M}$ and agitated for 1 hour at room temperature. The SMP washed again by water until the $\mathrm{pH}$ was neutral and dried in an oven with the variation of drying temperature for 4 hours. Rice straw that has passed through this stage is called BMP. BMP crushed and sieved with the mesh 75 (193.5 $\mu \mathrm{m})$.

Methylene blue is used as a waste simulation solution. Methylene blue solution was prepared by dissolving $4 \mathrm{mg}$ of methylene blue into $1 \mathrm{~L}$ of distilled water. Analysis of dissolved methylene blue concentration using UV-VIS spectrophotometer with maximum wavelength of $668 \mathrm{~nm}$.

\subsection{Experimental methods and measurements}

\subsubsection{Drying temperature}

Drying temperature variation is carried out in the second drying process. The temperature variation used are $60^{\circ} \mathrm{C}, 100^{\circ} \mathrm{C}$ and $140^{\circ} \mathrm{C}$. The second drying was done by using the oven for 4 hours.

\subsubsection{Biosorbent dosage}

Variation of dosage were performed by adding biosorbents of $0.1,0.5$, and $1 \mathrm{~g}$ to $300 \mathrm{ml}$ of methylene blue solution. The initial concentration of methylene blue solution used was $4 \mathrm{mg} / \mathrm{L}$. The adsorption studies was performed using a batch system in a $600 \mathrm{~mL}$ beaker glass that was stirred using a magnetic stirrer at $\mathrm{pH} 6$ and room temperature.

\subsubsection{Equilibrium studies}

The equilibrium studies is carried out by contacting the rice straw biosorbent with a methylene blue solution. The length of contact time is 2 hours with sampling every 5 minutes. The adsorption study was performed on a $600 \mathrm{~mL}$ beaker glass using a magnetic stirrer. Initial and equilibrium concentration were measured using a UV-VIS spectrophotometer with a wavelength of $668 \mathrm{~nm}$. The value of the adsorption equilibrium is calculated by the following formula.

$$
\mathrm{q}_{\mathrm{e}}=\frac{(c 0-C a) V}{W} \times 100
$$

Where $\mathrm{C}_{\mathrm{o}}$ and $\mathrm{C}_{\mathrm{e}}$ are initial concentration and equilibrium concentration, $\mathrm{v}$ is the volume and $\mathrm{m}$ is the dose of the biosorbent. Percent removal is calculated using the following formula.

$$
\text { Removal percentage }=\frac{C 0-C e}{C 0} x 100
$$

\subsubsection{Kinetics studies}

The kinetics studies is carried out by contacting $300 \mathrm{~mL}$ of methylene blue solution with different biosorbent doses. The studies was performed using a 600 $\mathrm{mL}$ beaker glass and magnetic stirrer at room temperature and $\mathrm{pH} 6$.

\subsubsection{Characterization of biosorbent}

There are two characterization performed in this research. The pore morphology on the surface of rice straw was observed using a Scanning Electron Microscopy with Energy Dispersive Spectroscopy (SEM EDS FEI type Quanta 650, Oxford). Then, functional groups on the surface of rice straw was analysed using a Fourier Transform Infra Red (FTIR Tensor 27, Brucker). FTIR spectra were recorded over the wavenumber range of $600-4000 \mathrm{~cm}^{-1}$.

\section{Results and Discussion}

\subsection{Scanning Electron Microscopy with Energy Dispersive Spectroscopy (SEM EDS)}

SEM characterization results were performed to analyze the pores which formed on the surface of the biosorbent shown in Fig. 2. Based on SEM test results, the pores formed on the surface of the biosorbent are not uniform. Pores are various in size, ranging from 14.08 to $20.57 \mu \mathrm{m}$. Pores on the surface of the biosorbent cause dye adsorption. The adsorbate particles will be trapped into the pores so that the adsorbate content in the waste simulation solution will decrease [10].

The element content on the biosorbent surface is detected by using EDS and presented in Table 1. The results obtained surface of the biosorbent are dominated by elements $\mathrm{C}, \mathrm{O}, \mathrm{Si}$ with a value of $58.07 \%$ atoms, $37.44 \%$ atoms and $3.35 \%$ atoms, respectively. These elements are involved in the adsorption process [11]. 


\subsection{Fourier Transform Infra Red (FTIR) Spectroscopy}

The result of fungsional group identification of biosorbent is shown in Fig. 3. Based on Fig. 3, peaks appeared at $1058 \mathrm{~cm}^{-1}$ and $1350 \mathrm{~cm}^{-1}$, which are represented $\mathrm{C}-\mathrm{O}$ stretching group and $\mathrm{C}-\mathrm{C}$ group. The absorbance band at $1650 \mathrm{~cm}^{-1}$ was assigned to $\mathrm{C}=\mathrm{O}$ stretching group. Then, the absorbance band at 2810 $\mathrm{cm}^{-1}$ and $3440 \mathrm{~cm}^{-1}$ was attributed to $\mathrm{C}-\mathrm{OH}$ stretching group and $\mathrm{O}-\mathrm{H}$ group, respectively. The results of the FTIR studies are summarized in Table 2.

\subsection{Influence of drying temperature}

The ability of rice straw biosorbent in dye absorbing is shown in Fig. 4. Biosorbent with $100^{\circ} \mathrm{C}$ and $140^{\circ} \mathrm{C}$ drying temperature has sorption capacities $95.27 \%$ and $94.39 \%$. Both types of biosorbents also reached a state of equilibrium at 30 minutes. While the biosorbent with a $60^{\circ} \mathrm{C}$ drying temperature, has a lower adsorption capacities of $88.47 \%$. The equilibrium state for biosorbent with $60^{\circ} \mathrm{C}$ drying temperature was reached at 95 minutes. If the drying temperature is higher, then the pores that formed on the surface of the biosorbent are more numerous as the amount of $\mathrm{H}_{2} \mathrm{O}$ and other volatile substances that can be evaporated is also more.

This relates to the number of active sites formed on the surface of the biosorbent [12]. The optimum drying temperature is specific for each type of biosorbent. Biosorbent with $100^{\circ} \mathrm{C}$ drying temperature has a higher \%sorption capacities when compared by biosorbent with $140^{\circ} \mathrm{C}$ drying temperature. This is because at a drying temperature of $140^{\circ} \mathrm{C}$ some of the biosorbent pores begin to damage, this is proven by the sorption capacities for biosorbent with a drying temperature of $140^{\circ} \mathrm{C}$ lower than the sorption capacities for biosorbent with a drying temperature of $100^{\circ} \mathrm{C}$ but not far adrift.

\subsection{Influence of Biosorbent Dosage}

The correlation between ability of rice straw biosorbent in absorbing methylene blue based on adsorbent dose is shown by figure 5 . In this analysis, a $100^{\circ} \mathrm{C}$ drying temperature biosorbent is used. As the adsorption studies proceeded, the adsorption capacities of rice straw biosorbent to the methylene blue is increased. The graph also explains that the more doses of biosorbent added, the more adsorbat absorbed. This is related to the number of active sites available [13]. Adsorption capacitiess for biosorbent at doses of 0.33 $\mathrm{g} / \mathrm{L}, 1.67 \mathrm{~g} / \mathrm{L}$ and $3.33 \mathrm{~g} / \mathrm{L}$ were $92.78 \%, 95.27 \%$ and $95.42 \%$, respectively. Based on the value of sorption capacities achieved, difference of sorption capacities value is not significant in the increase of biosorbent dose. This is because the availability of active sites at small doses is sufficient.

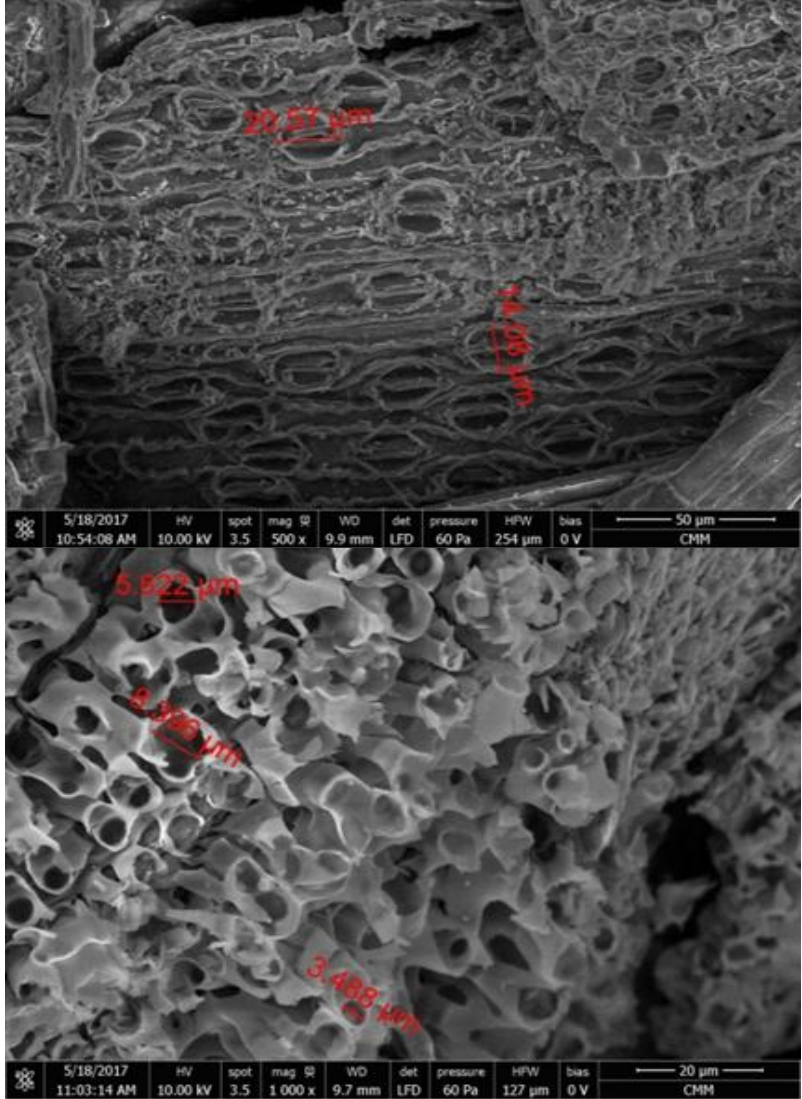

Fig. 2. SEM study of rice straw biosorbent in $100^{\circ} \mathrm{C}$ drying temperature with 500x magnification (above) and 1000x magnification (below).

Tabel 1. EDS study of rice straw biosorbent of $100^{\circ} \mathrm{C}$ drying temperature on spectrum 1 .

\begin{tabular}{lrrrl}
\hline Element & $\begin{array}{c}\text { Apparent } \\
\text { Concentration }\end{array}$ & $\mathrm{Wt} \%$ & Atomic \% & $\begin{array}{c}\text { Standard } \\
\text { label }\end{array}$ \\
\hline $\mathrm{C}$ & 12.01 & 47.53 & 56.51 & $\mathrm{C} \mathrm{Vit}$ \\
\hline $\mathrm{O}$ & 21.64 & 44.15 & 39.41 & $\mathrm{SiO} 2$ \\
\hline $\mathrm{Si}$ & 4.34 & 7.33 & 3.73 & $\mathrm{SiO} 2$ \\
\hline $\mathrm{Ca}$ & 0.56 & 0.99 & 0.35 & Wollastonite \\
\hline Total & & 100 & 100 & \\
\hline
\end{tabular}

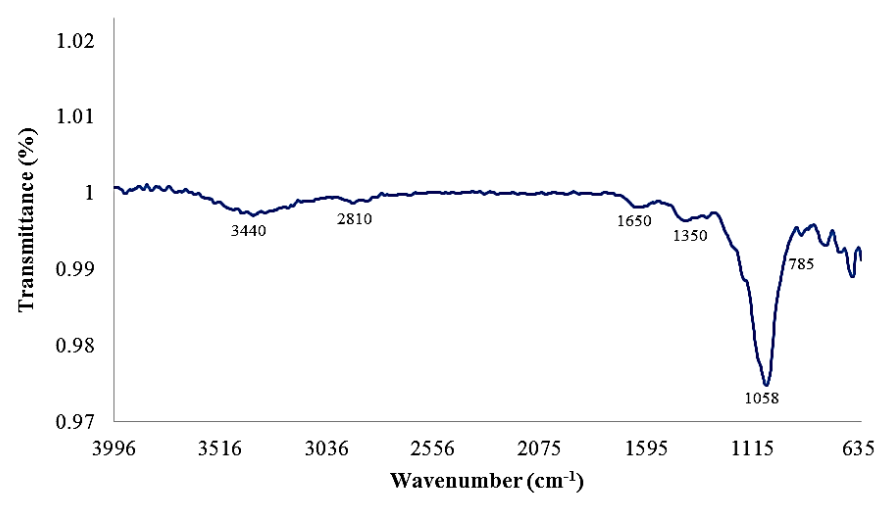

Fig. 3. FTIR study of rice straw biosorbent $100^{\circ} \mathrm{C}$ drying temperature. 
Tabel 2. The result of functional group analysis on rice straw biosorbent in $100^{\circ} \mathrm{C}$ drying temperature.

\begin{tabular}{ccccc}
\hline $\begin{array}{c}\text { IR } \\
\text { peak }\end{array}$ & $\begin{array}{c}\text { Frequency } \\
\left(\mathrm{cm}^{1}\right)\end{array}$ & $\begin{array}{c}\text { Functional } \\
\text { groups }\end{array}$ & $\begin{array}{c}\text { Type of } \\
\text { bond }\end{array}$ & Intensity \\
\hline 1 & 785 & Si-O & & \\
2 & 1058 & C-O & stretching & Strong \\
3 & 1350 & C-C & & Weak \\
4 & 1650 & C=O & stretching & Strong \\
5 & 2810 & C-OH & stretching & Weak \\
6 & 3440 & OH & & \\
\hline
\end{tabular}

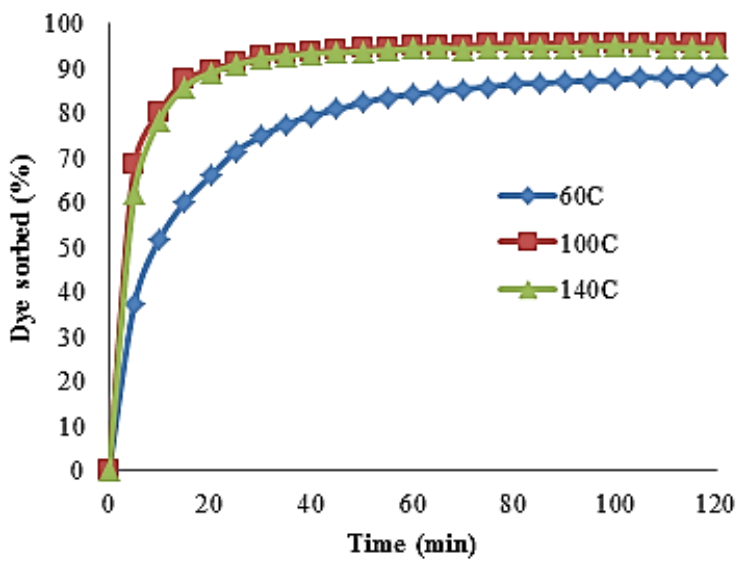

Fig. 4. Adsorption capacities of each rice straw biosorbent with a dose of $1.67 \mathrm{~g} / \mathrm{L}$ to $300 \mathrm{~mL}$ methylene blue.

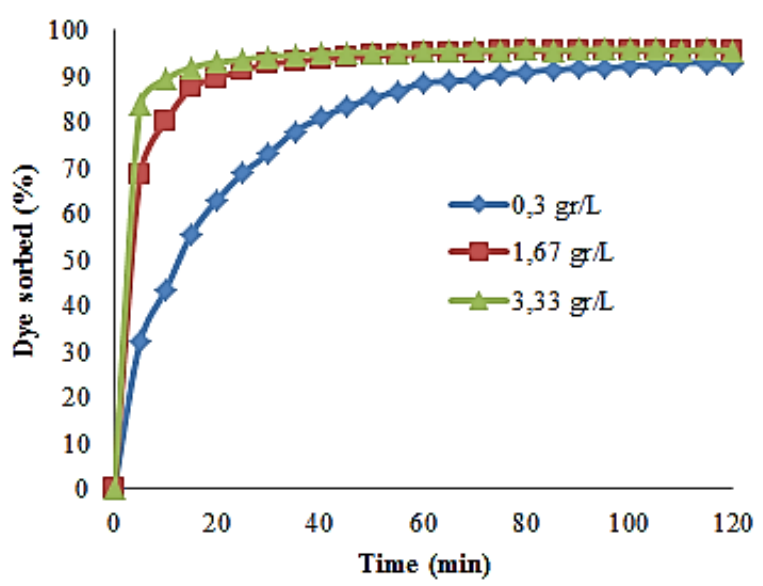

Fig. 5. Adsorption capacities of each rice straw biosorbent dose of $100^{\circ} \mathrm{C}$ drying temperature to $300 \mathrm{~mL}$ of methylene blue.

\subsection{Adsorption isotherm studies}

There are two isotherms equations used, Langmuir isotherm and Freundlich isotherm. Determination of appropriate isotherms based on the value of $\mathrm{R}^{2}$ which obtained.

Isotherm Langmuir explains the assumption that optimal adsorption occurs when the solute molecules formed a monomolecular layer on the biosorbent surface, constant adsorption energy, and no mass transfer of adsorbate molecules on the biosorbent surface. Isotherm Langmuir is expressed by the following equation.

$$
\frac{C e}{q e}=\frac{1}{q m K L}+\frac{1}{q m} \mathrm{Ce}
$$

$\mathrm{q}_{\mathrm{m}}$ and $\mathrm{K}_{\mathrm{L}}$ are Langmuir constants which represent the maximum adsorption capacity for solid phases and energy constants associated with the adsorption heat. While $\mathrm{q}_{\mathrm{e}}$ and $\mathrm{C}_{\mathrm{e}}$ describe the equilibrium condition.

Freundlich isoterm expresses an empirical relationship that explains the adsorption of solutes to the surface of the adsorbent and takes the assumption that the adsorbate formed a multimolecular layer on the biosorbent surface. Freundlich isotherm illustrates the relationship between the amount of adsorbat adsorbed per unit of adsorbent mass and the concentration of adsorbate at equilibrium.

$$
\log \mathrm{q}_{\mathrm{e}}=\log \mathrm{K}_{\mathrm{f}}+\frac{1}{\mathrm{n}} \log \mathrm{C}_{\mathrm{e}}
$$

$\mathrm{K}_{\mathrm{f}}$ and $\mathrm{n}$ are Freundlich constants, $\mathrm{K}_{\mathrm{f}}$ and $\mathrm{n}$ are indicators of adsorption capacity and adsorption intensity. While $\mathrm{q}_{\mathrm{e}}$ and $\mathrm{C}_{\mathrm{e}}$ describe the equilibrium condition.

The result of the analysis of $\mathrm{R}^{2}$ value for each biosorbent is shown in Tabel 3. Based on the calculation, biosorbent is more suitable with Langmuir isotherm equation. Langmuir isotherm curve can be seen in figure 6. The results of the Langmuir isotherm analysis show that the active surface of biosorbent has homogeneous properties and adsorbate is absorbed on the biosorbent surface forming a monomolecular layer.

\subsection{Adsorption kinetics studies}

The colour adsorption kinetics that occur between the adsorbate and the rice straw biosorbent progress quickly. At first the adsorption process that occurs is rapid adsorption. Then the adsorption process slows down over time and then enters a state of equilibrium.

Kinetic studies were analyzed using the kinetic equation of Pseudo Order 1 and the kinetic equation of Pseudo Order 2. Determination of corresponding kinetic based on the value of $\mathrm{R}^{2}$ which achieved. Kinetic equation of Pseudo Order 1 is shown in the following equation.

$$
\log \left(q_{e}-q_{t}\right)=\log q_{e}-\frac{k 1}{2.203} t
$$

$\mathrm{k}_{1}$ is a constant on the kinetic equation of Pseudo Order $1 . \mathrm{q}_{\mathrm{t}}$ and $\mathrm{q}_{\mathrm{e}}$ are the amount of adsorbate at $\mathrm{t}$ and at equilibrium.

The kinetic equation of Pseudo Order 2 is shown in the following equation.

$$
\frac{t}{q t}=\frac{1}{k 2 q e^{s_{2}}}+\frac{1}{q e} \mathrm{t}
$$


$\mathrm{k}_{2}$ is a constant on the kinetic equation Pseudo 2. $\mathrm{q}_{\mathrm{t}}$ and $\mathrm{q}_{\mathrm{e}}$ is the amount of adsorbate at time $\mathrm{t}$ and at equilibrium.

Based on the value of $\mathrm{R}^{2}$ in table 4 , the adsorption phenomenon that follows the kinetic equation of Pseudo order 2, which means that adsorption is chemical adsorption. Pseudo order 2 kinetics curve can be seen in figure 7 . The results of this study are similar to Kazembeigi's research [14].

Tabel 3. The value of $\mathrm{R}^{2}$ in the isotherm analysis of each biosorbent.

\begin{tabular}{crrr}
\hline \multicolumn{2}{c}{ Biosorbent } & \multicolumn{2}{c}{$\mathrm{R}^{2}$} \\
\hline \multirow{3}{*}{$\mathrm{T}(\mathrm{C})$} & Dose (gr) & Freunlich & Langmuir \\
\cline { 2 - 4 } 60 & 0.1 & 0.9308 & 0.876 \\
\cline { 2 - 4 } & 0.5 & 0.8818 & 0.9361 \\
\hline \multirow{3}{*}{100} & 1 & 0.9041 & 0.9748 \\
\cline { 2 - 4 } & 0.1 & 0.8274 & 0.9123 \\
\cline { 2 - 4 } & 0.5 & 0.8961 & 0.9912 \\
\hline \multirow{3}{*}{140} & 1 & 0.9504 & 0.9984 \\
\cline { 2 - 4 } & 0.1 & 0.8402 & 0.8729 \\
\cline { 2 - 4 } & 0.5 & 0.8895 & 0.9867 \\
\hline
\end{tabular}

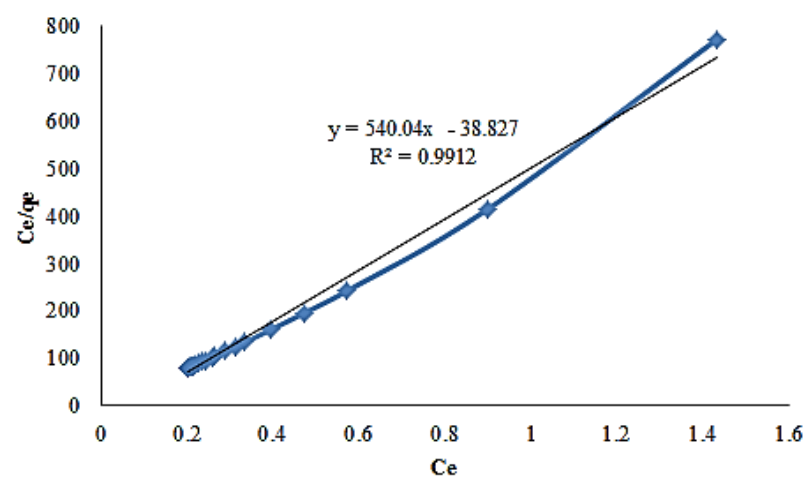

Fig. 6. Langmuir's isotherm curve for adsorption study with rice straw biosorbent $100^{\circ} \mathrm{C}$ drying temperature dose $0.5 \mathrm{~g}$ in 300 mLmethylene blue.

\subsection{Aplication of the biosorbent studied for water waste treatment}

The adsorption studies for batik industrial waste is carried out under the same conditions as using methylene blue, by using rice straw biosorbent temperature of $100^{\circ} \mathrm{C}$ and a dose of $0.5 \mathrm{~g}$ in $300 \mathrm{~mL}$ waste solution. Based on these studies can be seen the ability of biosorben rice straw of batik waste adsorption. The test results showed the dye sorbed increased. Sorption capacities achieved by $30.59 \%$.

Before the adsorption studies, pretreatment is performed for batik liquid waste. Pretreatment performed include sedimentation, filtration and centrifugation. The adsorption capacities of these studies is not as good as when using methylene blue solution.
This is because the substances dissolved in batik liquid waste waste are not only dyes, but many impurities such as azo dye, salts, waxes, and other impurities [15]. Salt contained in the waste solution is useful as a color amplifier, so that the color attached to the fabric does not quickly fade.

Tabel 4. The value of $R^{2}$ in the isotherm analysis of each biosorbent.

\begin{tabular}{|c|c|c|c|}
\hline \multicolumn{2}{|c|}{ Biosorbent } & \multicolumn{2}{|c|}{$\mathrm{R}$} \\
\hline $\mathrm{T}(\mathrm{C})$ & Dose (gr) & Pseudo order 1 & Pseudo Order 2 \\
\hline \multirow{3}{*}{60} & 0.1 & 0.9136 & 0.9996 \\
\hline & 0.5 & 0.9878 & 0.9983 \\
\hline & 1 & 0.9601 & 0.9641 \\
\hline \multirow{3}{*}{100} & 0.1 & 0.992 & 1 \\
\hline & 0.5 & 0.9807 & 0.9999 \\
\hline & 1 & 0.9743 & 0.9959 \\
\hline \multirow{3}{*}{140} & 0.1 & 0.9888 & 1 \\
\hline & 0.5 & 0.9671 & 0.9998 \\
\hline & 1 & 0.8502 & 0.9913 \\
\hline
\end{tabular}

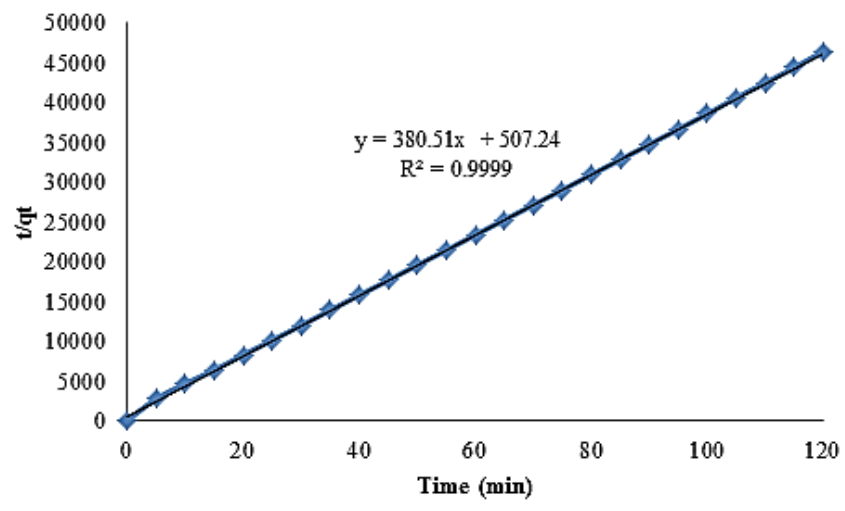

Fig. 7. Pseudo order 2 kinetic curve for adsorption study with rice straw biosorbent of $100^{\circ} \mathrm{C}$ drying temperature dose $0.5 \mathrm{~g}$ in $300 \mathrm{mLmethylene}$ blue.

\section{Conclusions}

This study confirmed that rice straw was excellent biosorbent for colour removal in liquid waste of batik industries which is represented by methylene blue. The optimum adsorption was in a $100^{\circ} \mathrm{C}$ drying temperature biosorbent at dose of $0.5 \mathrm{~g}$ in $300 \mathrm{~mL}$ of a 4 ppm methylene blue solution. The achieved of sorption capacities was $95.27 \%$ and reach equilibrium state after 30 minutes of adsorption. Sorption capacities that achieved for the adsorption studies using batik liquid waste was $30.59 \%$. The isotherm and kinetic equation of rice straw biosorbent adsorption are following the Langmuir isotherms and the kinetic Pseudo order 2. 
The authors thank BPPT (Badan Pengkajian dan Penerapan Teknologi) and BATAN (Badan Tenaga Nuklir Nasional) for analysis support.

\section{References}

1. T. Noorimotlagh, R.D.C. Soltani, A.R. Khataee, S. Shahriyar, H. Nourmoradi, J. Chin. Inst. Chem. Eng, (2014).

2. N. Colin, A. Maceda-Veiga, N. Flor-Arnau, J. Mora, P. Fortuno, C. Vieira, N. Prat, J. Cambra, A. de Sostoa, Ecotoxicol. Environ. Saf. 132, 295-303, (2016).

3. R.M. Jain, K.H.Mody, J. Keshri, B. Jha, Mar. Pollut. Bull. (2014).

4. Y. Wu, Y. Fan, M, Zhang, Z. Ming, S. Yang, A. A, P. Fang, Biochem. Eng. J. 105, 27-35, (2016).

5. S. Palsan, W.N.A.W. Jusoh, H. Subramanian, MATEC Web Conf. 87, (2017).

6. W.C.Li, F.Y. Law, Y.H.M. Chan, Environ. Sci. Pollut. Res. (2015).

7. W. Cao, Z. Dang, X.Q. Zhou, X.Y. Yi, P.X. Wu, N.W. Zhu, G.N. Lu, Carbohydr. Polym. 85, 571577, (2011).

8. C.G. Rocha, D.A.M. Zaia, R.V.S. Alfaya, A.A.S. Alfaya, J. Hazard. Mater. 166, 383-388, (2009).

9. S.A. Umoren, U.J. Etim, A.U. Israel, J. Mater. Environ. Sci. 4(1), 75-86, 2013.

10. A.A. El-Bindary, A.Z. El-Sonbati, A.A. Al-Sarawy, K.S. Mohamed, M.A. Farid, Spectrochim. Acta, Part A, 136, 1842-1849, (2015).

11. S.L.Wang, Y.M. Tzou, Y.H. Lu, G. Sheng, J. Hazard. Mater. 147, 313-318, (2007).

12. F.B. Scheufele, C. Ribeiro, A.N. Modenes, F.R.E. Quinones, R. Bergamasco, N.C. Pereira, Fiber Polym, 16, 1646-1656, (2015)

13. N. Nasuha, B.H. Hameed, A.T. Mohd Din, J. Hazard. Mater. 175, 126-132, (2010).

14. F. Kazembeigi, H.R.S. Arezoomand, H. Faraji, S. Mazloomi, F. Mohammadi, F.M.A. Moghadam, R. Khoshneyat, A. Nikonahad, H. Nourmoradi. Veliger. 53, 1-7, (2014).

15. M. Imran, D.E. Crowley, A. Khalid, S. Hussain, M.W. Mumtaz, M. Arshad, Rev. Environ. Sci. Biotechnol. 14, 73-92, (2015). 